\title{
O USO DE UM SOFTWARE DE SIMULAÇÕES PARA A APRENDIZAGEM DE CIRCUITOS ELÉTRICOS SIMPLES: UMA ABORDAGEM A PARTIR DO ENSINO POR INVESTIGAÇÃO
}

\author{
Marcelo Esteves de Andrade, Alfeu Scarpat Junior \\ LUiz OTAVIO BUFFON \\ Instituto Federal de Educação Ciência e Tecnologia do Espirito - Campus Cariacica
}

\begin{abstract}
Resumo
O presente artigo apresenta o relato de uma experiência envolvendo o ensino de circuitos elétricos simples, na disciplina de física, para uma turma de ensino médio. As atividades foram desenvolvidas a partir do uso do software simulador de circuitos elétricos EveryCircuit e foram aplicadas a partir da abordagem didática, conhecida como ensino por investigação. Nesta modalidade de ensino, os alunos são expostos a questões e problemas que devem ser resolvidos a partir da investigação de um dado fenômeno. Os alunos usaram o programa para construir e simular as situações físicas envolvendo os circuitos elétricos. Para mediar estas atividades de investigação foi utilizado o método POE - predizer, observar e explicar - de modo que as questões relativas à investigação didática fossem trabalhadas a partir desse método. Os resultados da aplicação nos indicam que as atividades promoveram de forma significativa a participação e envolvimento dos alunos com o objeto de estudo, mostrando também evidências de que os alunos se apropriaram dos conceitos relacionados ao tema de circuitos elétricos simples.
\end{abstract}

Palavras-chave: Circuitos Elétricos Simples, Simulação Computacional, Ensino de Física, Ensino por Investigação.

\footnotetext{
*E-mail: marcelo.andrade@ifes.edu.br
} 


\begin{abstract}
This article presents the report of an experiment involving teaching of simple electric circuits in the discipline of physics in a high school classroom. The activities were developed from the use of a program named EveryCircuit, circuit simulator software and were applied based on the studies known as Inquiry-Based Learning. In this teaching method students are exposed to questions and problems that must be solved with the investigation of a given phenomena. The students used the program to construct and simulate physical situations involving electric circuits and to mediate in these inquiry activities we used the POE method (to predict, observe and explain) so that the questions were worked out from this method. The results of the application showed that the activities promoted a significant participation and involvement of students with the object of study, as well as some evidence of effectiveness in learning the concepts related to the topic of simple electric circuits.
\end{abstract}

Keywords: Simple Electrical Circuits, Computational Simulation, Physics Teaching, Inquiry-Based Learning.

\title{
1 INTRODUÇÃO
}

No contexto do ensino contemporâneo as tecnologias da informação e comunicação- TIC's têm se destacado como ferramentas potenciais para ajudar alunos e professores na busca de um ensino mais dinâmico e eficaz. Porém, a velocidade na qual estas tecnologias são inseridas na vida cotidiana apresenta grande discrepância quando equiparada ao âmbito pedagógico.

Desta forma, a inserção da tecnologia na escola de modo a propiciar uma maior efetividade na condução do ensino ainda é um desafio; tanto para as escolas quanto para os professores e também para os alunos. A falta de preparação na formação inicial do professor, a falta de recursos adequados nas escolas e a baixa carga horária para o desenvolvimento destes tipos de atividades são alguns dos fatores que dificultam a aplicação de toda essa tecnologia no contexto da sala de aula.

$\mathrm{O}$ uso da tecnologia na sala de aula deve ser encarado não como um fim em si mesmo. Ele pode ser visto como uma ferramenta pedagógica que permite a exploração de situações, a partir do mundo virtual, que de outra forma não poderiam ser abordadas. Por sua vez, o uso destas ferramentas na sala de aula deve ser planejado, executado e avaliado, levando-se em conta os princípios e teorias contemporâneas de ensino, para que não se transforme apenas em um instrumento de informação ou entretenimento para os alunos.

De acordo com Veit e Teodoro (2002), a utilização destas novas tecnologias no contexto da sala de aula ainda está muito defasada em relação ao seu uso científico, necessitando que, para cada área específica do conhecimento, se incorporem as tecnologias no processo de ensino-aprendizagem. Orientações dos Parâmetros Curriculares Nacionais do Ensino Médio (BRASIL 1999) também apontam a importância da atualização no ensino em relação às TIC's, de forma que o professor seja levado a utilizar abordagens e metodologias de ensino mais atuais e mais eficazes, visando desenvolver as competências e habilidades do 
aluno, em cada disciplina.Um dos elementos que tem contribuído parcialmente para que esse cenário seja modificado é a implantação de mestrados profissionais voltados para professores, que visam exatamente levar o conhecimento das pesquisas em ensino para os docentes que estão em exercício nas salas de aula da educação básica.

Neste trabalho apresentamos uma proposta que visa enfrentar um problema muito comum vivenciado pelos professores de física em nível médio: a baixa compreensão conceitual dos alunos em relação aos conceitos iniciais envolvendo o estudo de corrente elétrica e circuitos simples. Para tanto, buscou-se desenvolver atividades com caráter investigativo a partir do uso de um software simulador de circuitos elétricos. Alguns trabalhos já têm apontado o potencial das atividades de simulação computacional para o ensino dos conceitos relacionados à carga, corrente e circuitos elétricos, como é o caso dos trabalhos de Dornelles, Araujo e Veit (2010) e também MACÊDO, J. A (2009).

O artigo está organizado da seguinte forma: Inicialmente abordamos os problemas enfrentados pelos alunos em relação aos conceitos básicos relacionados à eletricidade e suas concepções espontâneas. Em seguida falamos sobre o uso de simulações no ensino de física a partir do método investigativo Predizer, Observar e Explicar (POE). Na sequência, o artigo faz um detalhamento da proposta de ensino e de como ela foi aplicada em sala de aula. Por fim fazemos uma breve discussão dos resultados do desempenho dos alunos nas atividades e encaminhamos alguns procedimentos para aplicações futuras.

\section{AS CONCEPÇÕES DOS ALUNOS SOBRE CONCEITOS BÁ- SICOS DE ELETRICIDADE}

Alguns estudos sobre concepções alternativas realizados nas últimas décadas, como a pesquisa feita por Silveira, Axt e Moreira (1989), mostram que boa parte dos alunos tanto em nível médio como superior não apresentam conceitos cientificamente corretos quando se trata de temas como corrente elétrica, diferença de potencial e circuitos elétricos simples. Falando sobre alguns destes conceitos errôneos estes autores destacam que:

Entre as irregularidades já detectadas nessa área pode-se mencionar uma tendência a considerar corrente elétrica como uma noção primaria com características de energia e de substância: ela pode ser consumida e apresenta propriedades de um fluido material. (Silveira, Moreira e Axt 1989)

Num estudo mais recente, Dornelles, Araujo e Veit (2010) também destacam alguns tipos de raciocínio e dificuldades de aprendizagem em circuitos elétricos simples, dividindo estas dificuldades em dois aspectos: as dificuldades com os conceitos e as dificuldades devido a um modo errôneo de raciocínio. Os autores destacam algumas destas dificuldades:

Conceituais:

(a) Dificuldades relacionadas ao conceito de corrente elétrica.

(b) Dificuldades relacionadas ao conceito de diferença de potencial.

(c) Dificuldades relacionadas com conceito de resistência elétrica. 
(d) Concepções alternativas.

Modos errôneos de raciocínio:

(a) O uso de um raciocínio local em vez de sistemático ou holístico

(b) O uso de um raciocínio sequencial em vez de sistêmico ou holístico

Os autores indicam que há também um problema ligado à questão da linguagem dicotômica para um mesmo conceito no âmbito científico e seu uso no linguajar comum. Em geral esta diferença gera dificuldades na construção do conhecimento científico e o professor deve estar atento a este detalhe. É preciso que o professor esteja consciente destas dificuldades e que de alguma forma ele as leve em consideração no momento de se planejar as estratégias de ensino que serão aplicadas em sala de aula.

Silveira (2011) faz uma síntese das principais concepções alternativas, ou também chamadas de espontâneas, fazendo um paralelo com as concepções científicas, principalmente no que diz respeito ao entendimento sobre corrente elétrica e circuitos elétricos simples. Na Tabela 1 podemos ver como o autor destaca e descreve quatro "modos" destas concepções e insere ao lado a concepção científica correta. Podemos perceber que na descrição de cada uma delas vemos a presença de erros na definição, bem como nos modos de raciocínio sobre os circuitos, como já foi apontado.

Além dos aspectos ligados aos raciocínios errôneos por parte dos alunos neste tópico, existem também outras barreiras para a aprendizagem desta área, conforme sugerido por Santos e Fraga (2002) e Araújo (2011). Segundo estes autores, alguns conceitos relacionados com o Eletromagnetismo, como a carga elétrica, corrente elétrica e onda eletromagnética apresentam-se como elementos complexos e de difícil visualização; o que torna ainda mais difícil a compreensão destes temas por parte dos alunos.

Muitos docentes acabam por ignorar esta natureza epistemológica do ensino da física e isto acaba contribuindo para que as estratégias didáticas que serão implementadas em sala de aula não levem em consideração estas barreiras. O professor precisa então, numa ação reflexiva, planejar estratégias onde estudantes sejam levados deste conhecimento errôneo e espontâneo para o conhecimento científico. Isto perpassa desde a estratégia de planejamento como também a execução, avaliação e reensino, que por sua vez passa pelo planejamento macro (do curso como um todo) e micro (de cada aula e atividade desenvolvida) para o conteúdo em questão.

\section{O USO DE SIMULAÇÕES NO ENSINO DE FÍSICA A PARTIR DO MÉTODO INVESTIGATIVO POE}

Vários estudos têm mostrado (Oliveira, Araújo, Veit 2015, Santos e Sasaki 2015) que o engajamento ativo dos alunos nas atividades desenvolvidas em aula é um fator crucial para o aprendizado. No caso da aprendizagem de circuitos elétricos, uma possibilidade é o uso de atividades experimentais, onde os alunos podem explorar os circuitos elétricos num laboratório didático estruturado ou também construir com a ajuda do professor estes circuitos a partir de materiais como fios, lâmpadas e pilhas. Esta é uma alternativa muito interessante e que pode trazer muitos ganhos para a aprendizagem dos alunos. Porém, uma outra 
Revista do Professor de Física • Brasília, vol. 2, n. 2 • 2018

Tabela 1: Concepções alternativas versus concepções científicas sobre corrente elétrica (Silveira 2011 - Adaptado)

Paralelo entre concepções alternativas e científicas sobre corrente elétrica em circuitos simples de corrente contínua

Concepções Alternativas (Ou es- Concepções Cientificas

pontâneas)

1 - A corrente é uma forma de fluído produzido pela fonte ou gerador. A fonte é um depósito deste fluído, liberando-o para o circuito. A fonte produz ou armazena cargas para fornecê-las ao circuito.

2 - A corrente que "sai", que é "emitida"pela fonte (gerador) é uma propriedade exclusiva desta, não sendo afetada pelos demais elementos do circuito.

1 - A corrente elétrica é o movimento "ordenado"das cargas livres que pré-existem nos condutores. A fonte é responsável pelo campo elétrico que, exercido internamente aos condutores do circuito, coloca as cargas livres nos condutores em movimento "ordenado". A fonte não produz ou armazena cargas; a fonte libera energia para produzir o movimento "ordenado"das cargas livres que sempre existem nas diversas partes do circuito.

2 - A intensidade da corrente produzida pela fonte não depende apenas da fonte. A parte do circuito externa à fonte também influencia a intensidade da corrente na fonte. A mesma fonte pode produzir correntes elétricas com intensidades diferentes, dependendo do que foi conectado entre seus terminais.

3 - A corrente "desgasta-se", "dissipa-se" ao passar por "obstáculos"no circuito (lâmpadas, resistores, etc.), podendo até ser extinta caso passe por muitos "obstáculos". Conforme a corrente vai "passando" pelos "obstáculos", vai se tornando mais fraca.

4 - A intensidade da corrente elétrica é determinada pelo local em que ela "está passando"e pelos locais onde já "passou". Ela não pode ser influenciada pelos elementos onde ainda "não passou".

3 - A corrente conserva-se espacialmente. Não importando quantos elementos exista associados em série, a intensidade da corrente é a mesma em todos eles. Para que a intensidade da corrente elétrica seja diferente em regiões diversas de um circuito, deve existir um ou mais nodos ou divisores de corrente (associações em paralelo) entre essas regiões. Quando isto ocorre, a corrente se divide, entretanto a soma das intensidades da corrente nas diversas partes é necessariamente igual à corrente total.

4 - A intensidade da corrente elétrica em uma região do circuito depende de todo o circuito. O circuito é um sistema, isto é, modificando-se uma parte do circuito, altera-se a corrente em outras partes. Somente em situações muito especiais e idealizadas é possível alterar a intensidade da corrente elétrica em uma parte de um circuito sem alterar a intensidade em outras partes. 
alternativa é o uso de simulações para se trabalhar as mesmas situações das atividades experimentais; neste caso, com o uso do computador.

As vantagens do uso das simulações é que elas podem ser acessadas de forma mais fácil e mais rápida, sem a necessidade de um laboratório estruturado, ou da compra de materiais para a construção dos circuitos. Outro fator positivo é que numa mesma simulação se pode trabalhar com diversas situações diferentes, podendo incluir muitos elementos como resistores, capacitores ou lâmpadas; permitindo assim um nível maior de exploração e interação por parte dos alunos. O uso das simulações também elimina a possibilidade de acidentes ou queima de aparelhos.

É importante saber que as simulações também possuem suas limitações. Medeiros e Medeiros (2002) apontam para o fato de que geralmente um sistema físico real é muito complexo e as simulações que o descrevem são sempre baseadas em modelos que contêm necessariamente simplificações, nem sempre evidenciadas nas animações. Os autores também destacam que existe uma diferença significativa entre o ato de experienciar-se um fenômeno através de um experimento real e de uma simulação computacional. Estas observações não desqualificam o uso das simulações como ferramentas didáticas; elas apenas apontam que ao se fazer uso delas, o docente o faça com uma postura reflexiva e consciente de seu grau de ação e de suas limitações.

Um ponto crucial para o sucesso das atividades com as simulações é a metodologia empregada. Como já foi dito no início desta seção, o engajamento ativo dos alunos é um aspecto de crucial importância para a efetividade da proposta didática. Buscamos então, um referencial metodológico para o planejamento e execução das atividades que pudesse promover esse caráter mais ativo para o ensino. Escolhemos então a abordagem didática conhecida como "Ensino por investigação", que é uma proposta que já vem sendo utilizada há muitas décadas no ensino de ciências e fornece bons princípios para criarmos atividades que levem os alunos a um engajamento mais eficaz.

O termo ensino por investigação é muito amplo, mas em essência essa abordagem sugere que as atividades de ensino sejam mediadas não pela transmissão de conhecimentos do professor para o aluno mas, por uma construção do conhecimento mediada por questões e problemas propostos pelo professor, de modo que os alunos possam formular e testar hipóteses, discutir com seus pares e com o professor, construir argumentação, e passar da linguagem cotidiana para a linguagem científica. $O$ trabalho nesta abordagem com as atividades de simulação de circuitos sugere que os alunos deverão utilizar a ferramenta computacional como suporte para resolver questões e problemas propostos pelo professor sobre o assunto.

Para Carvalho (2014) uma atividade é chamada de investigativa quando ela apresenta situações problematizadoras, que proporcionem o questionamento e o diálogo, e que por sua vez envolvam a resolução de problemas e a introdução e discussão de conceitos. Esse ensino por sua vez deve desenvolver habilidades que visem a uma cultura científica, aproximando o aluno dos elementos-chave que se constituem em fazer ciência, tal como a elaboração de hipóteses, a estruturação do pensamento e a formalização do conhecimento a partir de sua sistematização, numa linguagem próxima a da ciência.

Dentre as ferramentas que podem ser usadas no desenvolvimento de atividades investigativas, Carvalho (2014) destaca que as atividades de simulação computacional são uma possível ferramenta para o desenvolvimento de uma sequência de ensino investigativa, mas que para que tenham um caráter investigativo, as atividades de simulação computacional devem ser preparadas e planejadas de modo que estimulem principalmente a característica problematizadora que esta modalidade de ensino possui. Arantes, Miranda 
e Studart (2010) enfatizam que em simulações mais elaboradas existe a possibilidade de se modificar diversas variáveis num dado fenômeno e observar os resultados provenientes destas modificações podendo então os alunos testarem as suas hipóteses sobre o tal fenômeno ao executar a simulação. Ainda discorrendo sobre estes aspectos metodológicos em relação à proposição das atividades de investigação para os alunos Sá, (2009) destaca que:

As atividades devem ser acompanhadas de situações problematizadoras, questionadoras e de dialogo, que levem os alunos a solucionarem os problemas e à introdução de conceitos para os próprios alunos construírem seu conhecimento. A ação do aluno é fundamental neste tipo de estratégia. Ele não deve se limitar somente na manipulação ou observação. Ele deve refletir, discutir, explicar e relatar, aplicando seus conhecimentos às novas situações.

Assim, podemos novamente afirmar que a ferramenta tecnológica por si só, mesmo que seja uma boa ferramenta, não consegue atender a todas estas demandas para o desenvolvimento de uma boa atividade, e que todas estas questões subjacentes não são apenas necessárias, mas constituem também um desafio para o docente ao planejar, executar e avaliar este tipo de atividades.

Para guiar o desenvolvimento das atividades, uma estratégia de ensino investigativo muito interessante é o chamado método POE, que propõe uma atividade de ensino exploratória através de três etapas: Predizer, Observar e Explicar (Tao e Gunstone 1999). Neste método o professor propõe uma situação-problema para os alunos individualmente ou em pequenos grupos de modo que a partir da interação com algum aparato experimental ou virtual eles possam resolver o problema a partir destas três etapas. Na primeira etapa os alunos devem formular hipóteses sobre o problema em si, ou seja, eles vão predizer o que acham que vai acontecer a partir de seus conhecimentos prévios ou intuitivos. Em seguida eles observarão o fenômeno, quer seja real, virtual ou até mesmo em vídeo. Por último os alunos devem buscar uma explicação para o ocorrido, mostrando a confirmação ou não de suas hipóteses, e esta explicação deve ser sistematizada e compartilhada com o professor e com os outros alunos numa discussão final. Neste sentido a proposição de questões adequadas ao nível intelectual dos alunos é fundamental, e esta por sua vez é a tarefa inicial do professor que irá em seguida conduzir o processo de estudo e aprendizagem.

Para desenvolver as atividades de construção e simulação de circuitos elétricos foi utilizado o programa EveryCircuit que é um software desenvolvido para fins educacionais. Ele possui uma plataforma que permite a utilização online sem a necessidade de instalação no computador ou também para dispositivos móveis como tablets e smartphones através de aplicativos que podem ser adquiridos em plataformas apropriadas. O programa possui uma versão demonstrativa gratuita com algumas funcionalidades limitadas, e também possui uma versão paga que dá acesso a todas as funcionalidades do programa. O usuário pode fazer o uso do programa e construir e explorar os circuitos elétricos a partir dos elementos disponíveis. $\mathrm{Na}$ Figura 1 é possível ver a área de trabalho do software com a simulação de um circuito simples contendo uma fonte de tensão, duas lâmpadas e um resistor.

O programa permite a construção dos circuitos a partir da inserção de vários elementos como fios, fontes de tensão, resistores, lâmpadas, entre outros. O usuário pode inserir e alterar os valores das grandezas, visualizando no próprio circuito o que acontece com as demais variáveis. É possível também visualizar os gráficos destas grandezas. 


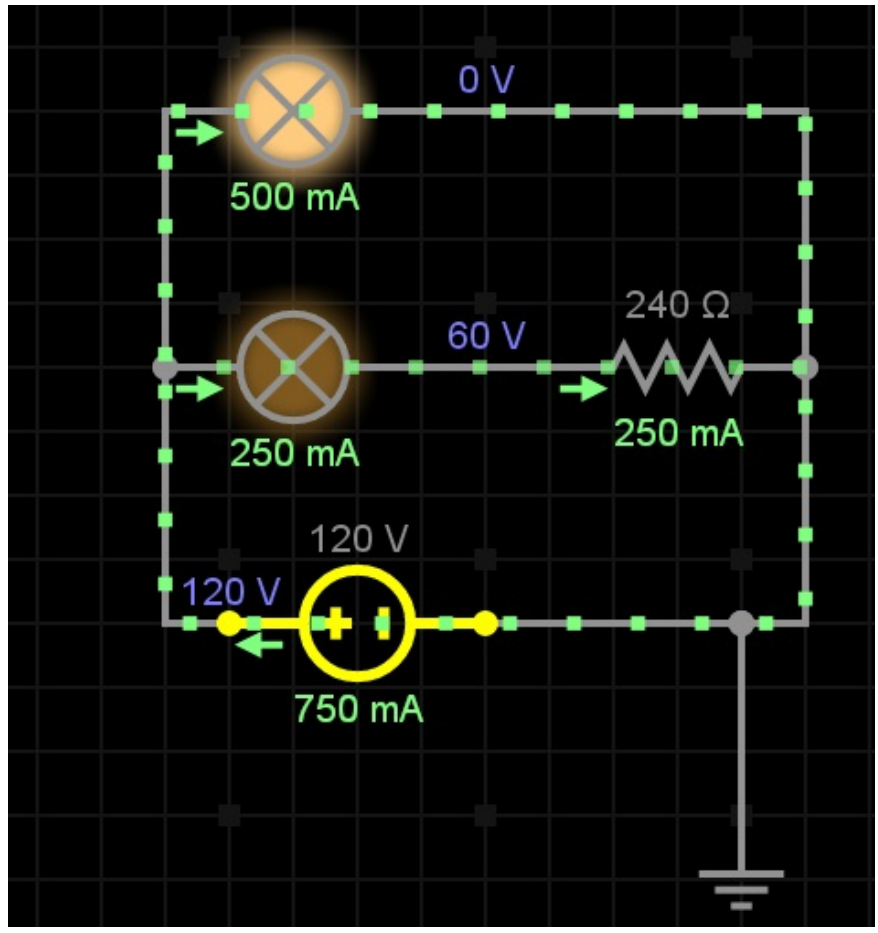

Figura 1: Simulação de um circuito simples no EveryCircuit - Versão livre.

\section{A METODOLOGIA DA PROPOSTA}

A proposta de ensino foi aplicada em uma turma regular de um curso técnico integrado ao Ensino Médio do Instituto Federal do Espírito Santo, Campus Cariacica no ano de 2016. Ao todo foram aplicadas quatro atividades computacionais envolvendo o uso do simulador EveryCircuit. As atividades desenvolvidas tinham como objetivo expor os alunos a situações que permitissem que eles explorassem os circuitos elétricos a partir das variáveis envolvidas e também sobre a relação existente entre elas.

As atividades computacionais propostas continham de três a quatro circuitos elétricos para serem analisados com base em questões-chave; situações problematizadoras específicas a cada circuito. Os grupos de alunos desenvolviam as atividades computacionais explorando os circuitos elétricos com base nas três etapas apresentadas pelo método POE e uma quarta etapa que envolvia o cálculo algébrico em relação a valores fornecidos para o referido circuito. Abaixo temos a descrição das etapas:

- Etapa 1: "Predizendo" - Nesta etapa a questão problema é proposta, ela é baseada em algum aspecto do funcionamento do circuito. O grupo de alunos tem que fornecer uma hipótese relativa a questão, e justificar a hipótese escolhida.

- Etapa 2: "Observando" - Nesta etapa o grupo de alunos constrói o circuito no simulador e observa o seu funcionamento em relação a questão apresentada na etapa 1.

- Etapa 3: "Explicando" - Nesta etapa os alunos devem apresentar uma explicação para o fenômeno 
observado que corrobora ou não a hipótese inicial feita. Caso necessário, eles devem revisar o argumento utilizado.

- Etapa 4: "Calculando" - Nesta etapa o grupo de alunos com base nos valores de tensões e correntes fornecidos no enunciado deve determinar valores de outras grandezas elétricas do circuito.

Ao final de cada atividade, uma discussão coletiva era realizada de modo a debater e sistematizar os resultados encontrados. Descreveremos aqui apenas duas destas atividades como exemplo, mostrando os aspectos principais da abordagem que também foram seguidos nas outras aplicações. Seguem então os exemplos dos enunciados das atividades computacionais que foram utilizadas.

Exemplo (1) A atividade consistia na análise de um circuito que incluía uma fonte de tensão, duas lâmpadas e um resistor.

No circuito abaixo considere as lâmpadas como resistores ôhmicos com potência nominal igual 60W/120V e tensão da fonte $120 \mathrm{Vdc}$ com resistência interna desprezível. Considere a resistência do resistor como sendo 240 ohms.

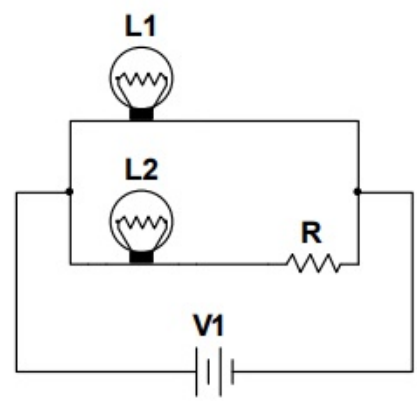

- Etapa 1: (Predizendo): Para o circuito da figura, diga qual das lâmpadas terá maior brilho ou quais terão brilho igual. Justifique sua hipótese.

- Etapa 2: (Observando). Monte o circuito da figura no simulador e observe o brilho das lâmpadas. O brilho observado condiz com a hipótese feita?

- Etapa 3: (Explicando). Caso haja diferença entre a hipótese e a observação explique a diferença. Revise o argumento utilizado.

- Etapa 4: (Calculando). Utilizando os dados fornecidos pelo simulador, mostre através de cálculo da potência, porque o brilho das lâmpadas se apresenta como o observado.

Exemplo (2) A atividade consistia na análise de um circuito que incluía uma fonte de tensão, duas lâmpadas e um resistor.

No circuito abaixo considere as lâmpadas como resistores ôhmicos com potência nominal igual 60W/120V e tensão da fonte $120 \mathrm{Vdc}$ com resistência interna desprezivel. Considere a resistência do resistor com sendo 240ohms. 


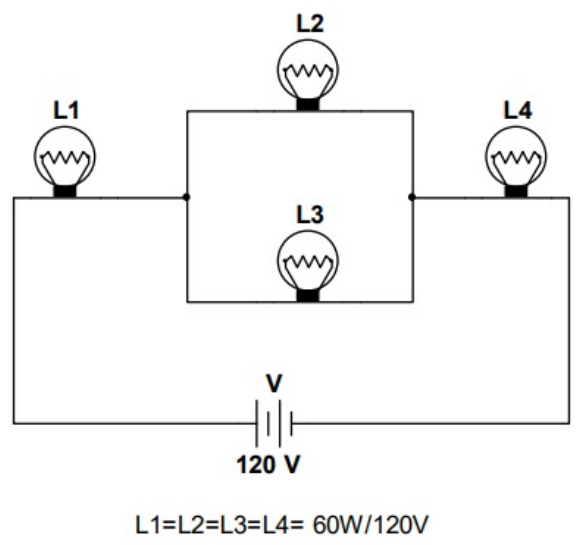

- Etapa 1: (Predizendo). No circuito da figura, quais lâmpadas terão maior, menor ou igual brilho? Justifique sua hipótese.

- Etapa 2: (Observando). Monte o circuito da figura no simulador e observe o brilho das lâmpadas. $\mathrm{O}$ brilho observado condiz com a hipótese feita?

- Etapa 3:(Explicando). Caso haja diferença entre a hipótese e a observação explique a diferença. Revise o argumento utilizado.

- Etapa 4: (Calculando). Utilizando os dados fornecidos pelo simulador, mostre através do cálculo da potência, porque o brilho das lâmpadas se apresenta como o observado.

A partir da proposição destas atividades, os grupos de alunos deveriam utilizar seus conhecimentos prévios e intuitivos sobre o tema para construir uma hipótese. A possibilidade de descrever uma hipótese e poder testá-la e visualizá-la no simulador muitas vezes gerava um conflito cognitivo que os alunos eram obrigados a rever seus argumentos iniciais sobre cada uma das situações. Nestes momentos, a discussão e troca de ideias entre os pares foi fundamental para que um novo argumento fosse construído, buscando uma leitura mais apropriada do que estava sendo observado.

Na primeira atividade aplicada, os alunos ainda mostravam algum grau de dificuldade em relação à construção do circuito no software. Neste momento o professor buscou auxiliá-los para que a tarefa fosse desenvolvida satisfatoriamente e que se dispensasse a maior parte do tempo na interpretação e discussão física do fenômeno. Nas atividades subsequentes estas dificuldades foram praticamente eliminadas.

Outra dificuldade inicial encontrada foi a postura dos alunos frente ao modelo de atividade investigativa. Uma vez que eles estão acostumados com o método tradicional onde o professor traz todas as respostas, observamos que era difícil para eles, principalmente nos momentos de bloqueio, não contar com uma resposta direta do professor, e ter que buscar através da reflexão e discussão as respostas para as questões propostas. Desta forma, várias vezes durante a aplicação, o professor enfatizava o caráter diferenciado destas atividades e a importância dele para a aprendizagem dos alunos, que aos poucos foram se adaptando a esta metodologia. 
Revista do Professor de Física • Brasília, vol. 2, n. 2 • 2018

Tabela 2: Categorização das respostas das atividades computacionais

\begin{tabular}{|l|l|l|l|}
\hline & \multicolumn{3}{|c|}{ Circuito 1 } \\
\cline { 2 - 4 } & Correta & Parcialmente Correta & Incorreta \\
\hline Hipótese & & & \\
\hline Explicação & & & \\
\hline
\end{tabular}

\section{ALGUNS RESULTADOS}

Para analisar as respostas dos alunos nas atividades de simulação utilizamos uma tabela de categorização ilustrada na Tabela 2. Tanto a hipótese como a explicação foram categorizadas de três formas: correta, parcialmente correta e incorreta. Após a realização de cada uma das atividades os questionários eram corrigidos e na aula seguinte era dado um retorno aos alunos.

O objetivo da intervenção, principalmente no momento em que os estudantes discutiam entre si e observavam a simulação, era o de levar os alunos a progredirem na qualidade das suas respostas, revisando ou refinando os argumentos. Pudemos perceber que grande parte dos grupos elevou o nível de suas respostas, passando do nível de incorreta para parcialmente correta, de parcialmente correta para correta e até de incorreta para correta. Observando os questionários percebemos que poucos foram os grupos que mantiveram o nível das respostas ao longo das atividades. Na Figura 2 temos um recorte de uma das atividades realizadas por um grupo de alunos, onde vemos a transição de uma hipótese incorreta para uma explicação correta.

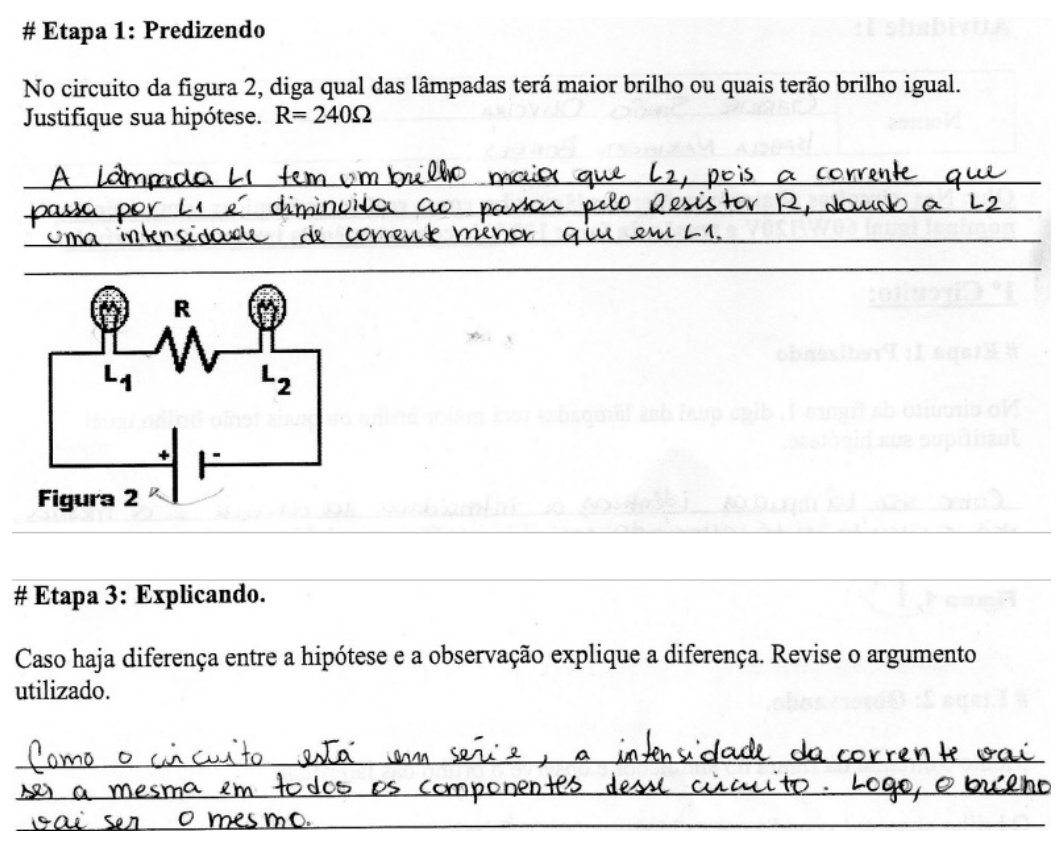

Figura 2: Descrição da hipótese e explicação para uma das atividades.

Ao final das atividades também aplicamos aos alunos um questionário de opinião, que pode ser 
Revista do Professor de Física • Brasília, vol. 2, n. 2 • 2018

Tabela 3: Questionário de opinião sobre a aplicação da proposta de ensino.

\begin{tabular}{|c|c|c|c|c|c|}
\hline \multirow{2}{*}{ Perguntas } & \multicolumn{5}{|c|}{ Escala (1 Pouco - 5 Muito) } \\
\hline & 1 & 2 & 3 & 4 & 5 \\
\hline $\begin{array}{l}1 \text { - "As atividades realizadas com o uso do simulador de cir- } \\
\text { cuitos elétricos despertaram o seu interesse para o assunto?" }\end{array}$ & 0 & 3 & 5 & 9 & 3 \\
\hline $\begin{array}{l}2 \text { "As atividades realizadas com o uso do simulador de cir- } \\
\text { cuitos elétricos contribuíram para o seu aprendizado dos } \\
\text { conceitos físicos sobre circuitos elétricos?" }\end{array}$ & 0 & 1 & 3 & 7 & 9 \\
\hline $\begin{array}{l}3 \text { "As atividades realizadas com o uso do simulador de cir- } \\
\text { cuitos elétricos o estimularam a participar mais ativamente } \\
\text { das aulas?" }\end{array}$ & 1 & 3 & 5 & 6 & 5 \\
\hline $\begin{array}{l}4 \text { "A metodologia de construção dos circuitos no simulador } \\
\text { contribuiu para o entendimento das situações?" }\end{array}$ & 0 & 0 & 2 & 8 & 10 \\
\hline $\begin{array}{l}5 \text { "A abordagem investigativa, de formular hipótese e de- } \\
\text { pois testá-las no simulador ajudaram no aprendizado sobre } \\
\text { circuitos elétricos?" }\end{array}$ & 0 & 0 & 2 & 7 & 11 \\
\hline $\begin{array}{l}6 \text { "A interação com o grupo na hora de responder as questões } \\
\text { facilitou a aprendizagem?" }\end{array}$ & 1 & 2 & 1 & 7 & 9 \\
\hline
\end{tabular}

visualizado na Tabela 3. A partir das respostas dos alunos extraímos uma breve ideia sobre a percepção deles nas atividades investigativas com o uso do simulador de circuitos. Observamos que para a maioria dos alunos, as atividades envolvendo o software simulador de circuitos elétricos foram muito importantes na aprendizagem, principalmente nos aspectos da construção dos circuitos no simulador e na abordagem investigativa. Na percepção deles ambos contribuíram para a compreensão dos conceitos físicos sobre circuitos elétricos, além de despertar o interesse pelo assunto. Nas perguntas propostas os alunos deveriam responder de acordo com uma pequena tabela que possuía uma escala de 1 a 5, onde 1 significa pouco e 5, muito.

Pela quantidade de respostas de alunos posicionados nos níveis 4 e 5, percebemos que na visão deles as atividades desempenharam um papel importante ao despertar o interesse pelo estudo do tema proposto, como também na própria aprendizagem do tema; não só no aspecto do uso das ferramentas computacionais, como também em relação a metodologia investigativa de ensino.

\section{CONSIDERAÇÕES FINAIS}

Este artigo apresentou a aplicação de uma proposta de ensino de circuitos elétricos simples utilizando a abordagem didática do ensino por investigação, no contexto de uma turma de Ensino Médio de um curso técnico integrado no Instituto Federal do Espírito Santo, no campus Cariacica. A estratégia de ensino centrada nos alunos propiciou um grande engajamento por parte deles no processo de desenvolvimento e construção de seus conhecimentos nos conceitos relacionados a circuitos elétricos simples. Através desta 
aplicação foi possível perceber o potencial das atividades de simulação e construção de circuitos para um aprendizado mais efetivo, atrativo e envolvente; o que ficou evidenciado na fala dos alunos.

Vale destacar que as atividades de simulação não podem ser vistas como substituição das atividades experimentais, mas sim que devem ser usadas de forma paralela e até quando possível de forma integrada. Apesar dos pontos positivos destacados, precisamos observar também, que aplicar estratégias de ensino deste tipo no contexto da escola brasileira atual ainda é um desafio para grande parte dos docentes, pois além de requerem um esforço maior no que diz respeito não só ao planejamento das ações e implementação das atividades, necessita também de recursos técnicos, maior carga horária, flexibilização do currículo, entre outros. A formação do professor para atuar com a tecnologia na sala de aula também é um obstáculo à inclusão das ferramentas digitais no ensino, pois sem o preparo adequado o professor não conseguirá extrair todas as potencialidades do uso eficaz dos recursos tecnológicos para promover uma aprendizagem com mais qualidade.

Desta forma, tanto os docentes, quanto a escola e também as instituições de formação devem buscar a superação destes obstáculos com estratégias inovadoras de ensino, usando a tecnologia como ferramenta mediadora cada vez mais presente no contexto do ensino da educação básica, com o propósito de alicerçar e promover o desenvolvimento dos alunos.

\section{Referências}

[1] ARANTES, A. R; MIRANDA, M. S; STUDART, N. Objetos de Aprendizagem no ensino de física: usando simulações do PheT. Física na Escola, 11, n. 1, 2010.

[2] ARAUJO, S. A. et al. Ambiente virtual de aprendizagem para apoio ao ensino de eletricidade para o ensino médio. In: SIMPÓSIO NACIONAL DE ENSINO DE FÍSICA, 19, 2011, Manaus. Atas... São Paulo: Sociedade Brasileira de Física, 2011. p. 1-9.

[3] BRASIL. Ministério da Educação, Secretaria de Educação Média e Tecnológica. PCN+- ENSINO MÉDIO, Orientações Educacionais Complementares aos Parâmetros Curriculares Nacionais. Brasília. 1999.

[4] CARVALHO, A. M. P. Calor e temperatura: Um ensino por investigação. São Paulo: Ed. Livraria da Física, 2014.

[5] DORNELES, P. F. T. Integração entre as Atividades Computacionais e Experimentais como Recurso Instrucional no Ensino de Eletromagnetismo em Física Geral. 2010. Tese de Doutorado. Instituto de Física, Universidade Federal do Rio Grande do Sul, Porto Alegre, 2010.

[6] MACÊDO, J.A. Simulações computacionais como ferramenta auxiliar ao ensino de conceitos básicos de eletromagnetismo: Elaboração de Um Roteiro de Atividades para Professores do Ensino Médio. 2009. Dissertação de Mestrado - Pontifícia Universidade Católica de Minas Gerais, Programa de Pós-Graduação em Ensino de Ciências e Matemática, Belo Horizonte, 2009. 
[7] MEDEIROS, A; MEDEIROS, C.F. Possibilidades e limitações das simulações computacionais no ensino da Física. Rev Bras Ens de Física, 24, n. 2, p. 77-86, 2002.

[8] OLIVEIRA, V; ARAUJO, I,S;VEIT, E. A. Relato de experiência com os métodos Ensino sob Medida (Just-in-Time Teaching) e Instrução pelos Colegas (Peer Instruction) para o Ensino de Tópicos de Eletromagnetismo no nível médio. Cad Bras Ens de Física, Florianópolis, 32, n. 1, p. 180-206, abr. 2015.

[9] SÀ, E. F. Discursos de professores sobre o ensino de ciências por investigação. 2009. Tese de Doutorado. Faculdade de Educação da Universidade Federal de Minas Gerais, Belo Horizonte, 2009.

[10] SANTOS, A. V.; SANTOS, S. R.; FRAGA, L. M. Sistema de realidade virtual para simulação e visualização de cargas pontuais discretas e seu campo elétrico. Rev Bras Ens de Física, São Paulo, 24, n. 2, p. 185-195, jun. 2002.

[11] SANTOS, R.J; SASAKI, D,G,G. Uma metodologia de aprendizagem ativa para o ensino de mecânica em educação de jovens e adultos. Rev Bras Ens de Física, São Paulo, 37, n. 3, set. 2002.

[12] SILVEIRA, F.L. Um teste para verificar se o respondente possui concepções científicas sobre corrente elétrica em circuitos simples. Publicado em Física no ensino médio: falhas e soluções. Organizador: Rocha Filho, J. B., Porto Alegre: Edipucrs, p. 61-67, 2011.

[13] SILVEIRA, F.L; MOREIRA, M.A; AXT, R. Validação de um teste para verificar se o aluno possui concepções científicas sobre corrente elétrica em circuitos simples. Ciência e Cultura, 47(11):112933p. Nov/1989.

[14] TAO, P.K., GUNSTONE, R.F. Conceptual Change in Science through Collaborative Learning at the computer. Intern J of Science Education. 21, n.1, pp.39-57, 1999.

[15] VEIT, E. A.; TEODORO, V. D. Modelagem no ensino/aprendizagem de física e os novos parâmetros curriculares para o ensino médio. Rev Bras Ens de Física, São Paulo, 24, n. 2, p. 87-96, jun. 2002. 